8 academic staff and focus groups with 14 pre-registration Children's Nursing students were undertaken.

Analysis Descriptive analysis of questionnaire data.

Thematic analysis of focus group and interview transcripts.

Key findings Young people identified factors (such as nurses' communication and clinical skills) which they considered to be important to the care they receive in $\mathrm{OOH}$ settings.

There is a wide variation in pre-registration Children's Nursing students' $\mathrm{OOH}$ clinical experiences.

There is a lack of consensus within and between HEIs, and nursing staff, in relation to the nature, duration and intended learning outcomes of $\mathrm{OOH}$ clinical experiences.

There is limited opportunity for post-qualification education.

There are significant challenges associated with the appointment of newly registered Children's Nurses to posts within OOH settings.

The presentation will be illustrated with participants' quotes.

\section{G13(P) A PROSPECTIVE REVIEW OF PSYCHOSOCIAL FUNCTIONING IN PARENTS OF INFANTS WITH COMPLEX CONGENITAL HEART DISEASE GOING HOME FOR THE FIRST TIME FOLLOWING FIRST STAGE CARDIAC SURGERY}

${ }^{1} \mathrm{KL}$ Gaskin, ${ }^{2} \mathrm{D}$ Barron, ${ }^{3} \mathrm{M}$ Rooney, ${ }^{3} \mathrm{~L}$ Cooper, ${ }^{3} \mathrm{~N}$ Mohammed. ${ }^{1}$ Department of Nursing, Midwifery and Paramedic Practice, University of Worcester, Worcester, UK; ${ }^{2}$ Department of Cardiac Surgery, Birmingham Children's Hospital, Birmingham, UK; ${ }^{3}$ Wellcome Trust Clinical Research Facility, Birmingham Children's Hospital, Birmingham, UK

\subsection{6/archdischild-2015-308599.13}

Aim The study presented here prospectively explores psychosocial adaptation and adjustment in parents going home for the first time with their infants following first stage cardiac surgery for complex congenital heart disease (CHD). Preliminary review of psychosocial functioning (anxiety, depression and confidence) and parent demographics in 15 parents (12 mothers, 3 fathers of 12 infants) enrolled into a feasibility study exploring the efficacy of home monitoring for infants born with complex CHD, will be presented.

Method Parents of infants being discharged from a specialist cardiac centre in the UK are recruited into a feasibility study, which commenced in August 2013 and ends in February 2015. The study is split into 3 randomisation arms: Group A were discharged home with weighing scales, a saturation monitor and a Congenital Heart Assessment Tool (CHAT); Group B were discharged home with the CHAT tool only and Group C were randomised to normal standard care. The parents are interviewed at 4 time points: T0 before discharge, T1 2 weeks post discharge, T2 8 weeks post discharge and T3 following the second surgical intervention (approximately 4-6 months post discharge). Baseline demographic data (family demographics, time of diagnosis, distance of specialist cardiac centre from home) is collected and parents are asked to complete the PHQ9, GAD7 and Maternal Confidence score (MCS) at each of the interviews. Results A preliminary review of the data collected from 15 parents, has demonstrated an improvement in anxiety, depression and confidence scores for all parents. Whereas some scores showed significant improvement a minority have shown a minimal increase in confidence scores. A more in depth analysis is currently being undertaken and these results will be available for display at the conference.

Conclusion This is the first study of its kind to prospectively explore parents' psychosocial adaptation and adjustment during the transition from hospital to home following first stage cardiac surgery. Despite the small number of families recruited into the study so far, the results provide an important insight into the discharge care and support these parents require. Implications for practice will be discussed.

Acknowledgement Study in collaboration with Little Hearts Matter, Heart Research UK and Coventry University (sponsors).

\section{G14(P) A COLLABORATIVE EDUCATIVE APPROACH TO INVEST IN ENABLEMENT OF TRANSITION: CLOSING THE GAP BETWEEN CHILDREN'S AND ADULT SERVICES}

${ }^{1,2} \mathrm{C}$ Gelder, ${ }^{1,3} \mathrm{C}$ MacArthur, ${ }^{1} \mathrm{~A}$ Phillips, ${ }^{2} \mathrm{~S}$ Morgan, ${ }^{1,2} \mathrm{~F}$ Campbell, 'S Redfern, ${ }^{1} \mathrm{~A}$ Smalley, ${ }^{1} \mathrm{~K}$ Rudd, ${ }^{1} \mathrm{P}$ Evans. 'Department of Health Sciences, University of York, York, UK; ${ }^{2}$ Leeds Childrens Hospital, Leeds Teaching Hospital NHS Trust, Leeds, UK; ${ }^{3}$ The Friarage Hospital, South Tees NHS Trust, Northallerton, UK

\subsection{6/archdischild-2015-308599.14}

Aims An overview of the creation, delivery, evaluation and impact of a collaboratively designed health professional degree and master's module supporting establishment, augmentation and enhancement of transitional services across long term conditions, life threatening illnesses, learning disability and mental health provision.

Methods A collaborative engaged multi-disciplinary module team with a combined vision to develop practitioners' knowledge, skills and abilities concerning effective transition opportunities worked together. We designed an interactive blendedlearning module supported by nationally recognised experts in the field, on-line resources and access to the RCPCH Adolescent health module.

The module was delivered and evaluated exceptionally well. Students were assessed design and presentation of their proposals to change and develop their services to be more 'adolescent and transition friendly'. The written assessment was a report to be delivered within the students areas of practice to facilitate the changes intended to realise development of effective transition services accordingly.

The module was delivered at level 6 and level 7 to support a multi-disciplinary team approach to embracing transition. Local Education Training Board (LETB) funding supported student attedance.

Results Students included Nurses, Doctors, Dietitians, Psychologists and Youth Workers evaluated the module excellently and highlighted opportunities realised within their own practices and specialisms. This demonstrated a change in thinking, renewed energy to face change and tackle potential challenges to providing effective transition. Synergistic opportunities were also realised by managers and commissioners attending the students' presentations and 'signing up' to supporting the fresh approaches and ideas within their services to enable effective transition to be appreciated.

Key outcomes for students and practice Developing a clearer vision through action planning, thus developing a wealth of knowledge and resources to stimulate change. Heightened motivation and confidence facilitated renewed energy to initiate practice communication with adult service colleagues.

Students had 'a voice' rather than hierarchy intimidating their vision for their team. The action plans met patients' needs for improvement and development to close service gaps.

Conclusion Quality transition services can be realised rather than just 'talked about'. Practitioners are engaged in critical 
discussions to effect this transformation and are implementing service improvement.

Crucially and incrementally managers and commissioners have pledged their support to escalate and influence essential changes in practice.

\section{G15 A ONE YEAR LONGITUDINAL STUDY ON EFFECTIVENESS OF STRATEGIES TO ENGAGE 'HARD TO REACH 'LOOKED AFTER CHILDREN'}

S Cope. Looked After Children, Heart of England Foundation NHS Trust, Birmingham, UK

\subsection{6/archdischild-2015-308599.15}

Guidance for Looked after Children (LAC) stipulates the requirement for detailed health assessments by specialised professionals on entry to care and regularly thereafter. However it was identified in 2012 that locally a high proportion of LAC consistently refused health assessments.

Aim To conduct a needs analysis and identify if new strategies could increase engagement and participation.

Method The specialist nurse for LAC contacted a randomised sample of 'health decliners', carers social workers collating reasons for refusal and feedback on suggested alternative approaches to address the issues. Reasons were categorised but general consensus was the current approach to health assessments was too clinical and rigid especially with venues and times. Many felt stigmatised resulting in non-compliance. The nurse drafted a 'decliner pathway' outlining a coordinated holistic response which included all key professionals and carers. Concurrently the nurse dip sampled nationally practice with assessments concluding a system wide re-think on practice (as below, Table 1) could benefit the whole LAC cohort:- different assessment documentation for children aged above nine increased holistic /less rigid focus alternative venues/times.

Subsequent informal and formal consultation with stakeholders, carers and cohort achieved agreement to pilot the decliner pathway and adapted practice*.

Results Based on a local LAC population of 366. Decliner cohort and therefore sample size was 75 .

$\begin{aligned} & \text { Abstract G15 Table 1 } \\
& 2013\end{aligned}$
\begin{tabular}{llll} 
Decliner interventions April & & \\
\hline Decliner & Number that & Number that & \% successful \\
referrals & engaged & remained decliner' & intervention \\
75 & 62 & 13 & 82 \\
\hline
\end{tabular}

*Study results were reported to all stakeholders.

Conclusion This study evidences adapted practice and strategies with operational and strategic input (NICE standards) led to increased engagement with this highly vulnerable group.

Increased access to specialised support may help empower, reduce health inequality potentially optimising positive future health outcomes.

\section{G16 INTRODUCTION TO THE WELL NORTH PROJECT AND THE POTENTIAL IMPACT ON CHILD HEALTH}

M Marshall, H Hurst. Central Manchester Foundation Trust, Manchester, UK

10.1136/archdischild-2015-308599.16
Background The Health of children in the UKis generally worse in the North of England where there are higher levels of child poverty. Evidence demonstrates that early disadvantages track forward, to influence health and development in later life and that children who start behind stay behind. Whitehouse (2014) and Marmot (2010) highlight the complexities and demonstrate a clear correlation between poverty, deprivation and poor health outcomes.

Aims The intention of this paper is to introduce a Public Heath England funded project for the North of England called 'Well North'. The overarching strategic aims of which are to:

Improving the health of the poorest fastestReducing levels of worklessness a cause and effect of poor healthReducing premature mortalityImproving health inequalities.

Method One of the unique key factors for this project is the engagement of the communities; understanding problem areas and reviewing best practices. Methodologies from the early phase will be presented in this paper.

Hot Spot Analysis. Pilot sites from across the region will be identified, within each of the pilot site a hot spot analysis will be undertaken to identify high rates of emergency hospital admissions. When matched against a combination of hospital and council data will identify socially and economically disadvantaged communities.

Appreciative Inquiry is a recognised method for studying and changing social systems that builds on the core aspirations that exist within an individual or group seeking to introduce change. Using the method the project team together with local community champions will explore the health attitudes, beliefs and behaviours of residents and multiple agency professionals living and working within these communities, seeking together to identify and implement a range of interventions that will improve the health and wellbeing of residents.

Conclusions This paper introduces only the early phase of the project. Ultimately, it is crucial that the end result of the project reduces health inequalities and in doing so produces a model of health and social care delivery that will enable every child to have the best start in life.

\section{G17 CHILDHOOD MULTIPLE SCLEROSIS: AN EXAMINATION OF FAMILIES EXPERIENCES, SUPPORT NEEDS AND CURRENT SERVICE MODELS IN THE UK}

S Kirk, D Hinton. School of Nursing, Midwifery and Social Work, University of Manchester, Manchester, UK

\subsection{6/archdischild-2015-308599.17}

Aims Increasing numbers of children and young people are being diagnosed with multiple sclerosis (MS). However, there is a lack of research about young peoples' and parents' experiences of living with MS and it is unknown how appropriate current support is for families. This presentation will report the findings from the first UK study that has explored the experiences and needs of parents and young people and examined the adequacy and appropriateness of services and support for this group of families.

Methods A qualitative approach (grounded theory) was taken. Semi-structured, in-depth interviews were conducted with 21 children/young people, 31 parents and 20 health-care professionals. The sample was recruited via health service and voluntary sector organisations across the UK. Data were analysed using the constant comparison approach. 